\title{
Sustainability in Materials Education
}

\author{
JEFFREY W. FERGUS, ${ }^{1,4}$ CHRISTOPHER TWIGGE-MOLECEY, ${ }^{2}$ \\ and JAMES MCGUFFIN-CAWLEY ${ }^{3}$ \\ 1.-Auburn University, Auburn, AL, USA. 2.-Hatch, Mississauga, ON, Canada. 3.-Case Western \\ Research University, Cleveland, OH, USA. 4.-e-mail: jwfergus@eng.auburn.edu
}

Consideration of the environmental and societal impacts of engineering products and processes is becoming increasingly important, so sustainabilityrelated issues need to be addressed in educating engineers. Awareness of sustainability issues is particularly important for materials and metallurgical scientists and engineers because they are involved in both developing processes and selecting materials with low-energy use and low environmental impact. In this article, activities at TMS to identify sustainability-related educational needs and opportunities to address these needs will be discussed.

\section{INTRODUCTION}

Sustainability is a very broad and interdisciplinary topic, which has different meanings for different people. While often the focus is on the environmental issues, the idea of sustainable development as "development that meets the needs of the present without compromising the ability of future generations to meet their own needs" resulting from the United Nations (UN) World Commission on Environment and Development ${ }^{1}$ broadened the perspective to consider economic and social issues over the long term. This triple bottom line (people-planet-prosperity) has received increasing attention. The recent UN Conference on Sustainable Development ${ }^{2}$ identified the importance of corporate participation and technology in promoting sustainable development.

Awareness of sustainability issues is particularly important for materials and metallurgical scientists and engineers because they are involved in both the supply and demand sides of sustainable technology. The supply side involves developing processes for the extraction, synthesis, and fabrication materials with low-energy use and low environmental impact, while the demand side involves considering these energy- and environmental-related issues including recycling and end-of-use in the selection of materials for engineering products.

\section{BACKGROUND}

In 2011, The Metals, Minerals and Materials Society (TMS) assembled an ad hoc committee to identify strategic areas in materials education to which TMS could contribute. One area identified by this committee was sustainability, so in 2012 , a subcommittee of the Materials and Society Committee focused on Sustainability in Materials Education was established.

The charge to the subcommittee was to gather information on current sustainability-related educational activities, identify needed sustainability-related knowledge and skills, and make recommendations for new TMS programs if warranted.

The first of the tasks was already being addressed by the American Institute of Mining, Metallurgical and Petroleum Engineers (AIME) Materials \& Resources Sustainability Steering Committee, which was compiling a list of sustainability resources. The work of this committee resulted in the Sustainable Engineering Education Key Resources Repository (SEEKRR) website. $^{3}$ Because the compilation of resources was being led by AIME, the TMS committee decided to support the AIME effort and move on to identifying sustainability-related educational needs for the metallurgical and materials engineering community.

\section{TMS MEMBER SURVEY AND INTERVIEWS}

The approach to assessing the sustainabilityrelated educational needs was to solicit input from TMS membership. Fortunately, TMS was planning a membership survey and was willing to append an optional survey for individuals from the industry who were interested in answering questions related to sustainability. ${ }^{4}$ The survey was sent by e-mail to TMS members in October 2012, and more than half (53\%) of the industrial respondents chose to answer 
To what extent is sustainability considered in the decision-making process for technical issues in your organization?

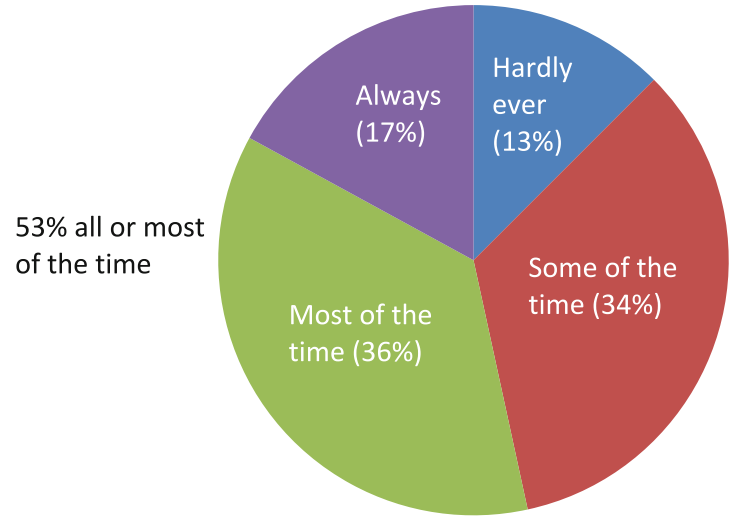

Fig. 1. Extent to which sustainability is considered in corporate decisions according to TMS member survey. ${ }^{4}$

the additional sustainability-related questions. These 89 respondents represent approximately $2 \%$ of the TMS members from the industry.

The results of the survey indicated that most companies considered sustainability in their decisions (Fig. 1) and have in place sustainability-related policies and procedures (Fig. 2). The respondents overwhelmingly ( $88 \%$ ) thought that the importance of sustainability would increase in the future.

Respondents were asked to indicate the "desired" and "actual" minimum levels of proficiency in nine sustainability topics on the following scale: none (0), conversant (1), proficient (2), and very proficient (3). The results are summarized in Table I, which shows that the desired levels fall in three groups with the following numerical ranges: $2.28,1.85-1.94$, and 1.49-1.59. In all cases, the "actual" proficiencies are lower than the "desired" proficiencies as illustrated in Fig. 3. Proficiency in energy efficiency had the highest priority with a score of 2.28 , indicating that the graduates should be "proficient" to "very proficient" in energy use and efficiency. The next group with scores closer to "proficient" than "conversant" includes life cycle analysis, recycling plus reuse, and corporate social responsibility.

The survey was followed by telephone interviews with eight senior individuals from a wide range of materials and metallurgical industries to confirm the results and provide additional insight on needs in sustainability education. The interviewees generally agreed with the ranking of importance of the sustainability-related topics. The one topic that seemed more important than indicated by the survey results was water use, which was ranked in the lower group from the survey but repeatedly came up during the interviews. The interviewees thought that corporate social responsibility was important, but less so than the others, in that a lower level of proficiency is needed. That is, awareness is adequate and generally is obtained from many public sources.
Does your organization have dedicated staff to deal with sustainability issues?

\begin{tabular}{|c|c|}
\hline Yes $(65 \%)$ & No $(35 \%)$ \\
\hline \multicolumn{2}{|c|}{$\begin{array}{l}\text { Is sustainability an issue explicitly considered in capital } \\
\text { investment proposals? }\end{array}$} \\
\hline Yes (72\%) & No $(28 \%)$ \\
\hline \multicolumn{2}{|c|}{$\begin{array}{l}\text { Does your organization have a defined and published policy on } \\
\text { sustainability and related issues? }\end{array}$} \\
\hline Yes (75\%) & No $(25 \%)$ \\
\hline \multicolumn{2}{|c|}{$\begin{array}{l}\text { Does your organization track success and expenditures in the } \\
\text { area of sustainability? }\end{array}$} \\
\hline Yes (67\%) & No (33\%) \\
\hline
\end{tabular}

Fig. 2. Emphasis of sustainability in organizations according to TMS member survey. ${ }^{4}$

The interviewees agreed that the importance of sustainability will increase in the future. In particular, regulations and licensing related to environmental impact are steadily becoming increasingly demanding. Also, in at least some of the interviews with supply chain engineers, the topic of sustainability was interpreted to include availability of mineral-based materials, which also seems to be an area of increasing focus.

In terms of the gap between the desired and actual proficiencies indicated by the survey results (Fig. 3), the interviewees agreed that additional preparation in these topics would be useful, but that most graduates learn what they needed on the job. There was some concern that additions to the engineering curricula would require removal of material, so such additions must be carefully considered to ensure that graduates still have a solid understanding of the fundamentals. However, enhancing preparation for working on multidisciplinary problems and in the global environment was identified as a need in response to changes in the scientific, engineering, technology, and business environments.

The on-the-job learning in which graduates engage would be facilitated with expanded continuing education opportunities. The needed topical areas, which align well with the results of the survey, include energy use, water use, and life cycle analysis.

\section{NEEDS AND OPPORTUNITIES}

Improving the preparation of scientists and engineers on sustainability-related issues can be provided during formal education or in postgraduation continuing education program.

One influence on formal engineering education is accreditation requirements. The engineering accreditation criteria of ABET specify 11 student outcomes that must be addressed in engineering curricula (Criterion 3). ${ }^{5}$ Sustainability and sustainability-related issues are specifically identified 
Table I. Results of TMS Member Survey ${ }^{4}$

\begin{tabular}{|c|c|c|c|c|}
\hline \multirow[b]{2}{*}{ Topic } & \multicolumn{2}{|c|}{ Desired } & \multicolumn{2}{|c|}{ Actual } \\
\hline & Average & Rank & Average & Rank \\
\hline Energy use and efficiency & 2.28 & 1 & 1.38 & 1 \\
\hline Recycling and reuse & 1.94 & 2 & 1.23 & 2 \\
\hline Life cycle analysis & 1.90 & 3 & 1.01 & 5 \\
\hline Corporate social responsibility & 1.85 & 4 & 1.03 & 4 \\
\hline Environmental law and responsibility & 1.59 & 5 & 0.85 & 9 \\
\hline Carbon management and climate change & 1.56 & 6 & 0.96 & 6 \\
\hline Industrial ecology & 1.50 & 7 & 0.91 & 8 \\
\hline Social and community issues & 1.50 & 7 & 1.11 & 3 \\
\hline Water and land use and reclamation & 1.49 & 9 & 0.96 & 6 \\
\hline
\end{tabular}

Desired (actual) minimum level of proficiency of new MSE graduates in each of the sustainability related topics listed above. None $=0$; conversant $=1$; proficient $=2$; very proficient $=3$.

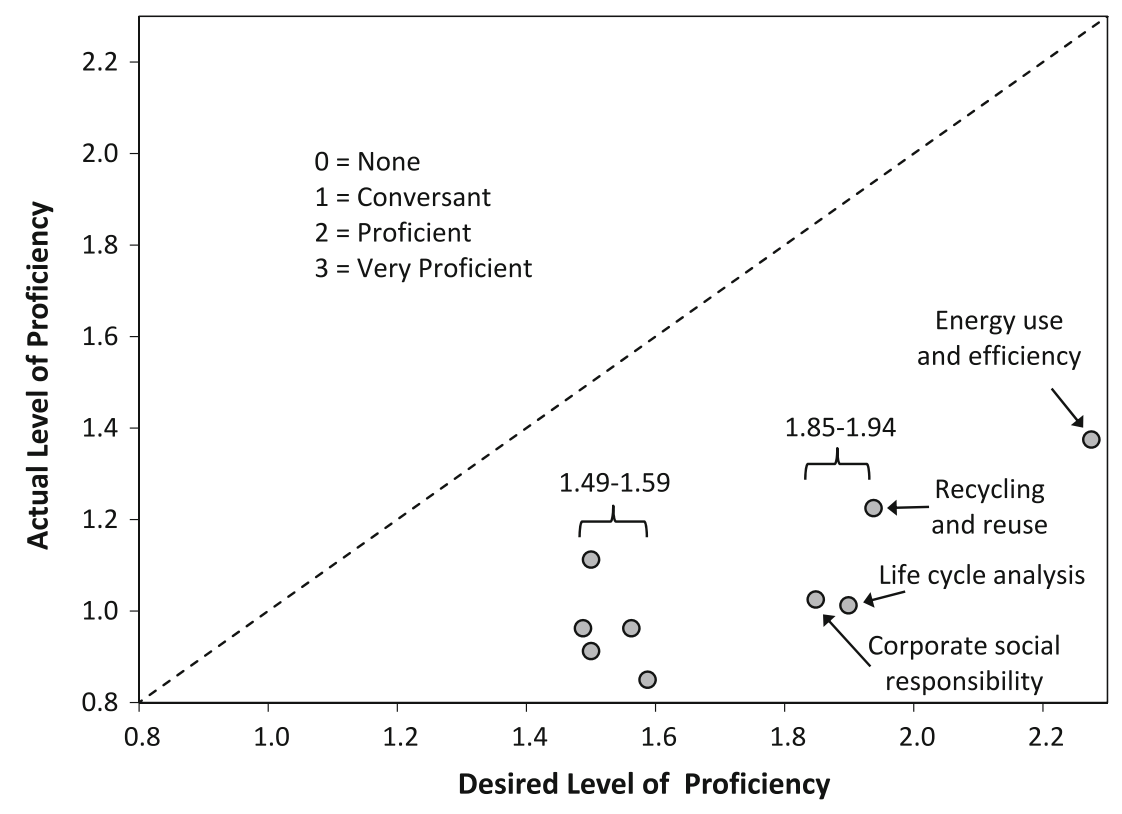

Fig. 3. The desired and actual proficiencies of graduates in sustainability-related topics according to TMS member survey. ${ }^{4}$

in two of these outcomes as listed below (emphases added):

(c) an ability to design a system, component, or process to meet desired needs within realistic constraints such as economic, environmental, social, political, ethical, health and safety, manufacturability, and sustainability.

(h) the broad education necessary to understand the impact of engineering solutions in a global, economic, environmental, and societal context.

Although specifically listed in the criteria, these issues are among many other requirements, so a relatively low level of coverage may be acceptable if other requirements are met. The more likely impetus for increasing coverage of sustainability-related issues is in response to Criterion $2{ }^{5}$ which requires that "the program must have published program educational objectives that are consistent with... the needs of the program's various constituencies." If the program's constituencies, which usually include alumni and employers of alumni, indicate that there is a need for enhancing preparation in sustainability-related topics, then the program will adjust its objectives and curriculum accordingly.

Curricular developments are typically made at the program level. However, professional societies can support these efforts by providing mechanisms for sharing information, such as the AIME SEEKER website $^{3}$ or by organizing education-related symposium at their meetings. Professional societies also organize and support continuing education programs to address the needs of their members.

The results of the TMS survey and subsequent interviews indicate that the most important sustainability-related topics are (i) energy use, 
(ii) water use, and (iii) life cycle analysis (including recycling and reuse). The first two topics are very broad, in which a wide variety of continuing education programs is currently available. While programs that focus on specific materials-related industries may be useful, there is a greater need for the materials community in the area of life cycle analysis. Some resources for workshops and courses related to life cycle analysis exist, ${ }^{6-9}$ but additional programs at professional society meetings would enhance availability and increase awareness of sustainability issues.

\section{CONCLUSIONS}

Sustainability is a very broad topic and has different meanings for different people. Although there may be some confusion over exactly what it is, there is no doubt that it is becoming increasing important. The multidisciplinary nature of sustainability creates challenges in covering the topics in formal academic programs, so targeted supplemental continuing education programs are needed and represent an opportunity for professional societies, including TMS, to meet the needs of their constituents.

\section{REFERENCES}

1. World Commission on Environment and Development, Our Common Future (Oxford: Oxford University Press, 1987).

2. United Nations Conference on Sustainable Development, The Future We Want, A/CONF.216/L.1 (United Nations, 2012).

3. AIME Sustainable Engineering Education Key Resources Repository (SEEKRR), http://www.aimehq.org/resources/seekrr.

4. Materials Sustainability Education Subcommittee Survey to TMS Membership, 2012.

5. Criteria for Accrediting Engineering Programs, 2013-2014, ABET, http://www.abet.org/DisplayTemplates/DocsHandbook. aspx?id=3149.

6. Granta Design, http://www.grantadesign.com/products/ecoaudit/ index.htm.

7. PE International, http://www.pe-international.com/america/ index/.

8. LCA from Harvard University School of Public Health, http://www.sciencenetwork.com/lca/index.cfm.

9. LCA Group of CSIRO, http://www.csiro.au/en/OrganisationStructure/Divisions/Process-Science-and-Engineering/MineralsLCA.aspx. 